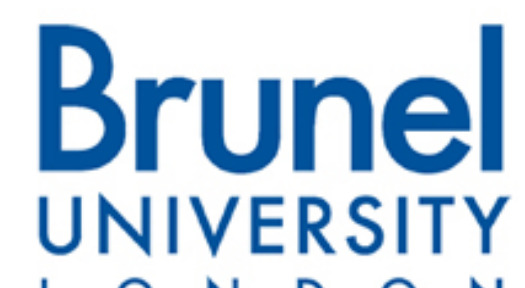

L O N D O N

Department of

Economics and Finance

Working Paper No. 13-04

Guglielmo Maria Caporale, Roberta De Santis and

¿ Alessandro Girardi

0

Trade I ntensity and Output Synchronisation: On the Endogeneity Properties of the EMU

March 2013

http://www. brunel.ac.uk/economics 


\title{
TRADE INTENSITY AND OUTPUT SYNCHRONISATION: ON THE ENDOGENEITY PROPERTIES OF EMU
}

\author{
Guglielmo Maria Caporale* \\ Brunel University, London, CESifo and DIW Berlin \\ Roberta De Santis \\ Italian National Institute of Statistics \\ Alessandro Girardi \\ Italian National Institute of Statistics
}

March 2013

\begin{abstract}
Using annual bilateral data over the period 1988-2011 for a panel of 24 industrialised and emerging economies, we analyse in a time-varying framework the determinants of output synchronisation in EMU (European Monetary Union) distinguishing between core and peripheral member states. The results support the specialisation paradigm rather than the endogeneity hypothesis. Evidence is found in the euro period of diverging patterns between the core and the peripheral EMU countries raising questions about the future stability of EMU.
\end{abstract}

JEL Classifications: F10, F15, F17, F4

Keywords: output synchronisation, trade intensity, endogeneity, European Monetary Union (EMU)

*Corresponding author. Department of Economics and Finance, and Centre for Empirical Finance, Brunel University, London, UB8 3PH, UK. Tel.: +44 (0)1895 266713. Fax: +44 (0)1895 269770. Email: Guglielmo-Maria.Caporale@brunel.ac.uk 


\section{Introduction}

The euro zone sovereign debt crisis following the recent financial turmoil has raised again the question of the sustainability of EMU and whether in its current form it can be considered an optimal currency area (OCA). In fact a number of recent studies (Chen et al., 2012; Schmitz and von Hagen, 2009; Sinn et al., 2011) concluded that during its first decade imbalances between member states and differences in business cycle patterns in the core and in the periphery increased.

As is well known, OCA theories (Mundell, 1961; McKinnon, 1963; Kenen, 1969) argue that the degree of synchronisation of national business cycles is an indicator of the cost of adopting a common currency and relinquishing monetary policy independence: the more synchronised they are, the more effective a common monetary policy is. Therefore, from a financial stability perspective, output synchronisation has crucial implications in the context of EMU, reducing the likelihood of asymmetric responses to shocks and thus increasing the effectiveness of “one fits all” ECB policies.

OCAs theories, however, do not provide formal criteria to evaluate whether the timing of the various steps necessary to create a currency area can be considered optimal, neither do they specify unique measures of the potential gains and losses. Individual OCA properties (e.g. labour and capital markets integration, price flexibility) as well as meta-properties aggregating several criteria have been considered. In the case of EMU, the positive impact of trade flows on output synchronisation predicted by Frankel and Rose (1998) has been analysed mainly in its very early stages (see the survey by Barbosa and Alves, 2011) - surprisingly, despite their availability, longer runs of data have not been used to test for long-run effects. 
The present study aims to fill this gap. Specifically, it draws on three different, though related, strands of empirical research. The first has examined the so-called “nominal convergence” criterion (Haug et al., 2000; von Hagen and Neumann, 1994; Antonucci and Girardi, 2006), highlighting some heterogeneity among countries in Stage III of the process of European integration. In particular, Haug et al. (2000) predicted potential problems in the long run for some peripheral countries (Italy, Portugal, and Spain) with the need for "potentially painful long-run policy adjustments and reforms” (Haug et al., 2000; p. 431).

A second strand has analysed the real aspects of monetary integration and the degree of synchronisation of national business cycles. Fatás (1997), using annual employment growth rates for various regions of France, Germany, Italy and the United Kingdom, found that the average correlation with aggregate EU-12 employment growth was higher in the period 1979-1992 than in previous one, 1966-1979. Similarly, Angeloni and Dedola (1999) reported that the output correlation between Germany and other European countries increased during the period 1993-1997, whilst Furceri and Karras (2006) estimated a higher business-cycle synchronisation for many countries in 1992-2003 compared to 1980-1991. Despite this evidence, the general overall conclusion emerging from more recent studies is that the "euro effect" on euro zone business cycles has been weak (Enders et al., 2010) or even null (Canova et al., 2009; Del Negro and Otrok, 2008; Giannone et al., 2009).

A third strand has stemmed from the heated debate between advocates of trade “specialisation” (Krugman, 1993; Krugman and Venables, 1996) theories and of the “endogeneity” hypothesis (Frankel and Rose, 1998) respectively. Economic theory does not provide unique predictions: stronger linkages could result either in a higher or a 
lower degree of business cycle co-movement depending on whether or not demand- and supply-side effects dominate over increased specialisation of production (Baxter and Kouparitsas, 2005; Imbs, 2006). In particular, the “specialisation” paradigm postulates that as countries become more integrated, their industrial structure develops according to their comparative advantages (Bayoumi and Eichengreen, 1996), and thus the economy of each member country of an OCA becomes more vulnerable to supply shocks. By contrast, according to the endogenous view of OCAs the positive link between income correlation and trade integration is magnified for countries joining a currency union, and therefore the conditions for an OCA might be satisfied ex-post even if they were not met ex-ante.

This paper, using annual bilateral data over the period 1988-2011 for a panel of 24 industrialised and emerging economies, contributes to the existing literature in three ways. First, unlike the existing studies covering a short time period after the launch of EMU, it analyses how the integration process affected output synchronisation over more than a decade. Such a time span is indeed necessary to capture the long-term developments induced by a monetary union, such as trade integration (De Santis and Vicarelli, 2007). Second, it adopts a time-varying framework to analyse the determinants of output synchronisation as previously done only in a few relevant studies (Kalemli-Ozcan et al., 2009; Imbs, 2010; Caporale and Girardi, 2012). Third, it distinguishes between core and peripheral economies and is therefore able to contribute to the debate on the "endogeneity" properties of EMU.

We show that the introduction of the euro has been associated with a decreasing role for trade intensity as a factor for output synchronisation within EMU. Furthermore, diverging patterns have emerged for the core and the periphery respectively which could 
represent severe obstacles to the well-functioning of EMU and raise questions about its future stability. The fact that more intense intra-EMU trade flows did not lead to greater convergence in economic developments across the euro area suggests that a higher degree of economic policy coordination between the euro area members is needed.

This paper is organised as follows. In Section 2 the empirical strategy is outlined. Sections 3 describe the dataset. Section 4 discusses the results of the timevarying analysis of the relationship between trade intensity and output synchronisation, as well as the evidence based on a number of alternative specifications. Section 5 offers some concluding remarks.

\section{The empirical strategy}

Since the study of Frankel and Rose (1998) a large body of empirical research (Clark and van Wincoop 2001; Calderon et al. 2007; among others) has shown that bilateral trade flows (tra) can affect output synchronisation $(\rho)$ across countries and/or regions. Following this literature, a canonical regression model can be specified as

$$
\rho=\varphi_{1} \operatorname{tra}+\varepsilon
$$

The positive effect of bilateral trade flows on the degree of international business cycle synchronisation has been widely confirmed in the most recent literature even when controlling for other possible determinants, such as capital flows or industry specialisation (Imbs, 2004, 2010, Baxter and Kouparitsas 2005, Böwer and Guillemineau, 2006, Inklaar et al., 2008).

However, standard international business cycle models have difficulty in matching the Frankel and Rose (1998) empirical results, leading to a "tradecomovement puzzle” (Kose and Yi 2006). According to standard theory, trade intensity 
has an ambiguous effect on the co-movement of output. Openness to trade will lead to increased specialisation in production and inter-industry patterns of international trade. If business cycles are dominated by industry-specific shocks, trade-induced specialisation leads to decreasing business cycle correlations. However, if trade is dominated by intra-industry trade industry-specific shocks may lead to more symmetric business cycles. Consequently, the positive link between trade and business cycle synchronisation is often seen as an indication that intra-industry dominates interindustry trade as a spillover channel for shocks. ${ }^{1}$

When testing condition (1) empirically, output synchronisation is typically measured by filtering variables measuring the level of activity (i.e. real output or industrial production indices) over a selected window, ranging from a few years (Mathy and Meissner, 2011) to several decades (Frenkel and Rose, 1998). Here instead we follow Giannone et al. (2009) and measure the degree of synchronisation as the negative of divergence in growth rates, defined as the absolute value of GDP $(y)$ differences between country $i$ and $j$ in a given year $t$ :

$$
\rho_{i t}^{(t)}=-\left|\Delta \ln y_{i}^{(t)}-\Delta \ln y_{j}^{(t)}\right|
$$

This index is not subject to the criticism of various filtering methods and makes it possible to assess the degree of output synchronisation on a year-by-year basis rather than as an average of multi-year windows.

Concerning trade intensity, we follow Frankel and Rose (1998) and employ total trade between two countries scaled by total GDP or total trade. Accordingly, we compute (a time-varying version of) bilateral trade intensities as

\footnotetext{
${ }^{1}$ For the specific case of euro area, intra-industry is found to be very relevant by Di Giovanni and Levchenko (2010).
} 


$$
\operatorname{tr} a_{i j}^{(t)}=\frac{x_{i j}^{(t)}+m_{i j}^{(t)}}{z_{i}^{(t)}+z_{j}^{(t)}}
$$

where $t$ is a time index, $x_{i j}^{(t)}$ denotes total merchandise exports from the $i$-th (reporting) EMU economy to its $\mathrm{j}$-th trading partner (namely the rest of EMU countries as well as other relevant economies taken as a control group), $x_{i j}^{(t)}$ represents total imports of the $i$ th EMU country from its $j$-th trading partner, and $z_{i}^{(t)}$ and $z_{j}^{(t)}$ are the nominal GDP levels in the two economies.

While the qualitative conclusions concerning the impact of trade on income correlation are generally not dependent on the exact measure chosen (i.e. Calderon et al., 2007; Inklaar et al., 2008), the main problem in correctly estimating it is that trade intensity is endogenous. This makes simple ordinary least squares (OLS) regressions of bilateral economic activity correlation on trade intensity inappropriate. Frankel and Rose (1998) deal with this problem by using gravity variables (i.e. shared border, common language dummies or log-values of distance) as instruments to identify the effect of trade on business cycle correlation. Owing to the endogeneity of trade, instrumental variables (IV) techniques are commonly employed in order to identify accurately the effects of trade on business cycle co-movement.

In contrast to the empirical literature started by Frenkel and Rose (1998) estimating condition (1) over a span of several years, we run for each country pairs $i j$ a sequence of cross-sectional regressions based on the following fixed effects model:

$$
\rho_{i j}^{(t)}=\alpha_{i}+\varphi_{1}^{(t)} \operatorname{tr} a_{i j}^{(t)}+\varepsilon_{i j}^{(t)}
$$

for $t=1, \ldots, T$, where $\alpha_{i}$ collects the fixed country effects. Condition (4) sheds light on whether and how the relationship between trade intensity and output synchronisation might have changed over time, and therefore on the real effects of monetary integration. 
In order to analyse them in greater depth, we also run several regression with interaction effects

$$
\rho_{i j}^{(t)}=\alpha_{i}+\varphi_{1}^{(t)}\left(I_{k}\right) t r a_{i j}^{(t)}+\varphi_{2}^{(t)}\left(1-I_{k}\right) t r a_{i j}^{(t)}+\varphi_{3}^{(t)} I_{k}+\varepsilon_{i j}^{(t)}
$$

with $k=1, \ldots, 5$ where the $k$-th binary indicator takes value one (and zero otherwise) for: (a) pairs of countries both belonging to EMU $(k=1)$, in order to disentangle genuine intra-area effects from the influence of extra-EMU developments; (b) pairs of countries both in EMU but with the reporting economy being a core European country $(k=2)$ or a peripheral European country $(k=3)$ respectively, in order to investigate whether there are diverging patterns between core and peripheral countries as recently shown by Lehwald (2012); and (c) pairs of countries both in the core $(k=4)$ or in the peripheral EMU ( $k=5$ ) respectively, as would be implied by a two-speed Europe, with only Germany, its smaller neighbours (including Austria), and France forming a viable monetary union (see von Hagen and Neumann, 1994).

\section{Data and descriptive statistics}

Data on bilateral trade are taken from the IMF's Direction of Trade Statistics (DOTS) database for bilateral exports and imports in US dollar terms. Our preferred measure of real economic activity is real GDP, and the relevant series have been obtained from the OECD Structural Analysis (STAN) database. The data are annual and span the period from 1988 to 2011.

The reporting countries are the following EMU member states: Austria, Belgium Finland, France, Germany, Greece, Ireland, Italy, the Netherlands, Portugal, Spain. ${ }^{2}$

\footnotetext{
${ }^{2} 1999$ marks the beginning of the euro period for all countries but Greece, who joined in 2001. Given the small size of their economies relative to the euro area as a whole, the omission of later entrants (namely
} 
The partner economies are the same countries listed above as well as industrialised (Australia, Canada, Denmark, Japan, Korea, Norway, New Zealand, Sweden, Switzerland, the UK and the US) and emerging economies (Brazil, China, India, Russian Federation) as a control group named Rest of the World (ROW). Following the literature (von Hagen and Neumann, 1994; Caporale and Girardi, 2011) we define Austria, Belgium, Finland, France, Germany and the Netherlands as "core” and Greece, Ireland, Italy, Portugal and Spain as peripheral EMU countries, respectively.

Table 1 reports some descriptive statistics for the variables employed in the empirical analysis for the full sample of countries as well as for several sub-groups identified according to the criteria discussed in Section 2 above. As expected, EMU country pairs exhibit a larger degree of synchronisation in real activity. Moreover, output developments in core EMU countries appear to be closely related to those in their EMU partners, especially in the other core EMU members. By contrast, the peripheral countries exhibit a much lower degree of output synchronisation and a much higher level of variability.

\section{[Table 1]}

Figure 1 (Panel A) plots the evolution of output synchronisation over the time span considered, by distinguishing patterns for EMU country pairs and for the EMU members vis-à-vis the ROW. On average, a "Europe” rather than a "euro" effect can be detected: a higher degree of output co-movements for EMU pairs can be observed more clearly during the years before the start of Stage III of EMU rather than after the introduction of the euro. However, differences between core and peripheral countries 
(Panel B and C, respectively) emerge, notably a relative increase in output synchronisation for the core countries with respect to the rest of the euro area and to the other core countries, except for the year 1991, which marks German reunification. In the peripheral countries, output synchronisation decreases in relative terms with respect to both the euro area and the other peripheral countries.

[Figure 1]

As for trade patterns, Figure 2 largely confirm the trends described above for output synchronisation. When comparing EMU pairs with respect to the ROW, however, the positive "Europe" effect over the whole period is reinforced by a "euro" effect starting from 2003 (Panel A). Again, different patterns can be observed for the core and peripheral countries (Panel $\mathrm{B}$ and $\mathrm{C}$, respectively): the lack of flexible exchange rates and of an independent monetary policy as well as fiscal policy constraints appear to have generated asymmetric responses of the core and the periphery to external shocks.

\section{[Figure 2]}

\section{The econometric analysis}

\subsection{Estimation results}

The stylised facts discussed above corroborate the view of the lack of an "euro" effect reducing asymmetries in business cycle developments within EMU (Enders et al., 2010; Canova et al., 2009; Del Negro and Otrok, 2008; Giannone et al., 2009). Interestingly, our evidence indicates that, despite the increase in trade intensity after the launch of the euro, diverging patterns in real activity and heterogenous behaviour in trade flows can 
be detected. This finding supports the specialisation paradigm of Krugman (1993) rather than the endogeneity hypothesis of Frankel and Rose (1998). ${ }^{3}$

In order to gain a deeper understanding of the output-trade linkage, we estimate models (4) and (5) as a sequence of fixed effect cross-sectional regressions for each year from 1988 to 2011. To address the endogeneity issue of trade intensity we use as external instruments, following the traditional gravity approach, the (log of) distance and its squared term, the presence of a common border and common languages, the (log of) the size of the partner country and a dummy for tariffs proxied by the membership to WTO (source: CEPII and WTO). ${ }^{4}$ Moreover, as the residual $\varepsilon_{i j}$ may suffer from possible heteroscedasticity owing to measurement errors specific to a given country $j$, we follow Imbs (2010) and control for this possibility via clustering of the residual along the reporting country dimension.

Tables A.1-A.6 in the Appendix report the fixed effect estimates, with coefficients in bold and italics indicating statistical significance at the 5 and 10 percent nominal level (or better), respectively. In brief, the coefficient associated with trade intensity is found to be positive and statistically significant in the majority of cases. Furthermore, according to the p-values associated to the Hansen-J statistics the instruments are uncorrelated with the disturbances.

While useful to assess possible time-varying effects in the trade-output nexus, the estimation results in Tables A.1-A.6, the outcome of $T \times(k+1)=144$ different

\footnotetext{
${ }^{3}$ According to theory, the effect of trade intensity on output co-movement is ambiguous. Close trade relations between countries may affect the business cycle through demand fluctuations, as changes in income in one country will normally also lead to a change in the demand for foreign goods.

${ }^{4}$ All instruments are taken from: http://www.cepii.fr/CEPII/en/bdd_modele/presentation.asp?id=8.
} 
fixed effects models, is clearly hard to interpret. Moreover, year-by-year estimations of the impact of trade intensity on output synchronisation are likely to be influenced by shocks hitting the system in a specific year. In order to provide an overview of the results, we analyse the time series averages of the yearly slopes, along with their standard errors corrected for serial correlation as suggested by Petersen (2009). ${ }^{5}$

According to the results in Table 2, in the period 1988-2011 the average relationship between trade intensity and output synchronisation for the EMU countries and the ROW is positive and highly significant, in line with the empirical literature surveyed by de Haan et al. (2007). Since the trade intensity measure is expressed in logarithms and the dependent variable in percentage points, the estimates in Table 2 can be interpreted as semi-elasticities. For instance, the coefficient of about 0.65 for the full sample implies that an increase in bilateral trade intensity of one percent (roughly the value of its sample standard deviation as reported in Table 1) leads to an average increase in output synchronisation of 0.7 . Given the (absolute) median value of output synchonisation of 1.7 (see Table 1), these are significant effects in economic terms as well.

[Table 2]

\subsection{Rolling averages}

The aggregate picture, however, could hide some dynamic heterogeneity in the tradeoutput relationship. With this in mind, we analyse the behaviour of the coefficient over time, through rolling averages (over a 5-year window) of the estimated coefficients in

\footnotetext{
${ }^{5}$ More formally, let $\beta^{(t)}$ be a time series of the estimated slope, with $t=1, \ldots, T$. Its average value is given by $\frac{1}{T} \sum_{i=1}^{T} \beta^{(t)}$, whilst its corrected standard error is given by $\frac{1+\theta}{1-\theta} \sigma^{2}$, where the variance $\sigma^{2}$ is equal to the (square of) the standard deviation of $\beta$ divided by $\sqrt{T}$, where $\theta=\operatorname{corr}\left(\beta^{(t)}, \beta^{(t-1)}\right)$.
} 
Tables A.1-A.6. Considering the whole period (Figure 3), it can be seen that the rolling estimates of $\gamma_{1}$ in model (4) lie in the interval between 0.5 and 1.1. Interestingly, before 1999 there was a decreasing trend in this coefficient, followed by stability.

\section{[Figure 3]}

To shed further light on these findings we extend the baseline model (4) by discriminating between EMU country pairs and ROW economies. The rolling estimates for the coefficients $\gamma_{1}$ (solid line) and $\gamma_{2}$ (dashed line) of specification (5), with $k=1$, are presented in Figure 4. After an increase in the average value in the pre-euro period, a slightly declining trend can be observed more recently. In particular, the effect of trade intensity on output synchronisation within the EMU appears to have declined in the euro period. This behaviour is consistent with the historical European experience, with trade relationships between countries being affected not only by past investment in export-oriented infrastructure, but also by the accumulation of invisible assets such as political, cultural and geographical factors influencing commercial transactions within this area. Close trade linkages characterised the economies adopting the euro even previously (De Nardis et al., 2008a, 2008b).

\section{[Figure 4]}

To obtain more disaggregate results we re-run model (5) distinguishing between EMU core and peripheral countries. Panel A and B of Figure 5 report the estimates of $\gamma_{1}$ and $\gamma_{2}$ for the case of $k=2$ (dashed lines) and $k=3$ (dotted lines), respectively. The estimates of the former are very similar for both sub-groups, suggesting that trade shocks originating outside EMU produce similar responses in both. By contrast, the coefficient $\gamma_{1}$ appears to be fairly stable in the core countries but very unstable in the peripheral ones, where it is increasing before the introduction of the euro and decreasing 
afterwards. Therefore, the declining trend in the semi-elasticities for EMU country pairs of Figure 4 can be ascribed almost entirely to the peripheral EMU countries.

\section{[Figure 5]}

Similar evidence is provided by Figure 6, where the $\gamma_{1}$ and $\gamma_{2}$ coefficients for EMU core and periphery country pairs, that is model (5) with $k=4$ (dashed lines) and $k=5$ (dotted lines) respectively, are presented. These findings suggest the existence in the euro period of both output synchronisation (see, for instance, Lehwald, 2012) and more structural differences. More specifically, it seems that trade intensity has led to higher business cycle correlation only among the core countries, but not in the case of the periphery. Structural factors (such as inter- versus intra-industry trade) not included in our empirical framework could account for this phenomenon. However, on the whole it is clear that, after more than a decade from the launch of the EMU, trade flows within the area are having a decreasing effect on the business cycle correlation between member states, i.e. the endogeneity mechanism has not been very effective. This is consistent with the evidence based on pre-euro data (Haug et al., 2000; von Hagen and Neumann, 1994), and favours the specialisation theory of Krugman (1993) rather than the endogeneity hypothesis of Frankel and Rose (1998).

\section{[Figure 6]}

\subsection{Robustness}

To assess the robustness of the finding of a declining effect of trade intensity on output synchronisation in the euro period, we also consider three alternative specifications to models (4) and (5). ${ }^{6}$ First we estimate regressions where the indicator of output synchronisation is based on industrial production instead of GDP growth rates. As

\footnotetext{
${ }^{6}$ Complete estimation results are available on request.
} 
pointed out by Imbs (2010), the former is an imperfect measure of overall economic activity, capturing only a share of it. Moreover, it largely abstracts from non-traded goods. Since our analysis covers periods of turmoil (i.e. the European Monetary System breakdown, the Asian crisis and the recent global financial crisis), a measure focusing on traded goods (as in the case of GDP) is more appropriate. The results are qualitatively similar to those discussed in Section 4.2: the semi-elasticities for trade intensity are positive and statistically significant in the vast majority of year-by-year regressions; the effect of trade intensity on output synchronisation within EMU is slightly declining in the euro period; a symmetric response of output synchronisation to trade shocks originating outside EMU is again found for EMU core and peripheral countries; in the peripheral EMU economies the trade-output nexus is not stable, increasing before the introduction of the euro and declining afterwards.

The other two robustness checks are based on using different trade intensity measures. Following Frankel and Rose (1998) we construct alternative indicators as follows: a) by scaling the numerator of (3) by the sum of total imports and exports instead of the sum of nominal GDP of the generic pair $i j$; b) by using only exports when computing the alternative indicator given by a). Again, the general conclusions arising from the baseline model estimate are largely confirmed.

\section{Conclusions}

The recent financial crisis has raised some doubts about the euro zone being an OCA. This paper analyses how trade integration has affected output synchronisation since the introduction of the euro using bilateral annual data over the period 1988-2011 for a 
panel of 24 industrialised and emerging economies. This is a crucial issue for the effectiveness of a single monetary policy and financial stability.

Our findings show that the relationships between trade intensity and output synchronisation is positive and statistically significant (with a few exceptions). Moreover, the evidence of a declining effect over time, and in the euro years in particular, supports the specialisation model of Krugman (1993) in preference to the endogeneity hypothesis of Frankel and Rose (1998). Further, the increasing divergence between the core and the periphery raises questions about the future stability of EMU. It appears that more intense intra-EMU trade flows do not guarantee greater convergence in economic developments across the euro area. From a policy perspective, this calls for a higher degree of coordination between the euro area members.

Further interesting issues to be addressed are whether a smaller set of countries would qualify as an OCA and whether structural factors (such as inter- versus intraindustry trade) would explain better the endogeneity properties of the EMU. These questions are beyond the scope of the present paper and will be the subject of future research. 


\section{References}

Angeloni I and L. Dedola, 1999. From the ERM to the euro: new evidence on economic and policy convergence among EU countries. ECB Working Paper, 4.

Antonucci D. and A. Girardi 2006. Structural changes and deviations from the PPP within the euro area. Applied Financial Economics 16, 185-98.

Barbosa R. and R.H. Alves, 2011. The euro area ten years after its creation: (divergent) competitiveness and the optimum currency area theory. Panoeconomicus 58, 605629.

Baxter M. and M. Kouparitsas 2005. Determinants of business cycle comovement: a robust analysis. Journal of Monetary Economics 52, 113-157.

Bayoumi T. and B. Eichengreen., 1996. Ever closer to heaven? An optimum-currencyarea index for European countries. CIDER Working Papers, C96-078.

Böwer U. and C. Guillemineau, 2006. Determinants of business cycle synchronisation across euro area countries, ECB Working Paper, 587.

Calderon C., A. Chong and E. Stein, 2007. Trade intensity and business cycle synchronization: are developing countries any different? Journal of Internation Economics 71, 2-21.

Caporale G.M. and A. Girardi, 2011. Fiscal spillovers in the euro area. CESifo Working Papers, 3693.

Caporale G.M. and A. Girardi, 2012. Business cycles, international trade and capital flows: evidence from Latin America. CESifo Working Papers, 4006.

Canova F., M. Ciccarelli and E. Ortega 2009. Do institutional changes affect business cycles? Evidence from Europe. Universitat Pompeu Fabra Economics Working Paper, 1158. 
Chen R., G.M. Milesi-Ferretti, T. Tressel 2012. External imbalances in the euro area. IMF Working Paper, 236.

Clark T.E. and E. van Wincoop 2001. Borders and business cycles. Journal of International Economics 55, 59-85.

De Haan J., R. Inklaar, and O. Sleijpen, 2002. Have business cycles become more synchronized? Journal of Common Market Studies 40, 23-42.

Del Negro M. and C. Otrok, 2008. Dynamic factor models with time-varying parameters: measuring changes in international business cycles. Federal Reserve Bank of New York Staff Report, 326.

De Nardis S., R. De Santis R. and C. Vicarelli, 2008a. The single currency's effects on eurozone sectoral trade: winners and losers? Economics-e-Journal Journal, Article 17.

De Nardis S., R. De Santis R. and C. Vicarelli, 2008b. The euro's effects on trade in a dynamic setting. European Journal of Comparative Economics 5, 73-85.

De Santis R. and C. Vicarelli, 2007. The “deeper" and the “wider” EU strategies of trade integration. An empirical evaluation of EU common commercial policy effects. Global Economy Journal 7, Article 4.

di Giovanni J. and A.A. Levchenko, 2010. Putting the parts together: trade, vertical linkages, and business cycle comovement. American Economic Journal: Macroeconomics 2, 95-124.

Enders Z., P. Jung and G.J. Müller, 2010. Has the euro changed the business cycle? Austrian Central Bank Working Paper, 162.

Fatás A. 1997. EMU: countries or regions? Lessons from the EMS experience. European Economic Review 41, 743-751. 
Frankel J.A. and A.K. Rose, 1998. The endogeneity of the optimum currency area criteria. Economic Journal 108, 1009-1025.

Furceri D. and G. Karras, 2006. Are the new EU members ready for the euro? A comparison of costs and benefits. Journal of Policy Modeling 28, 25-38.

Giannone, D., M. Lenza and L. Reichlin, 2009. Business cycles in the euro area. CEPR Discussion Paper, 7124.

Haug A.A., J.G. MacKinnon and L. Michelis, 2000. European monetary union: a cointegration analysis. Journal of International Money and Finance 19, 419-432.

Imbs J., 2004. Trade, finance, specialization and synchronization. Review of Economics and Statistics 86: 723-734.

Imbs J., 2006. The real effects of financial integration. Journal of International Economics 68: 296-324.

Imbs J., 2010. The first global recession in decades. IMF Economic Review 58, 327354.

Inklaar R., R. Jong-A-Pin and J. De Haan, 2008. Trade and business cycle synchronization in OECD countries, a re-examination. European Economic Review 52, 646-666.

Kalemli-Ozcan S., E. Papaioannou and J.L. Peydro, 2009. Financial integration and business cycle synchronization, NBER Working Paper, 14887.

Kenen P., 1969. The theory of optimum currency areas: an eclectic view. In (Mundell R. and A. Swoboda eds.) "Monetary Problems in the International Economy", Chicago: University of Chicago Press, 41-54.

Kose M.A. and K. Yi, 2006. The trade comovement problem in international macroeconomics. Federal Reserve Bank of New York Staff Report, 155. 
Krugman P.R., 1993. “Geography and Trade”. Cambridge, MA: MIT Press.

Krugman P.R and A.J. Venables, 1995. Globalization and the inequality of nations. The Quarterly Journal of Economics 110, 857-880.

Lehwald S., 2012. Has the euro changed business cycle synchronization? Evidence from the core and the periphery. IFO Working Paper, 122.

Mathy G.P. and C.M. Meissner, 2011. Business cycle co-movement: evidence from the great depression. Journal of Monetary Economics 58, 362-372.

McKinnon R., 1963. Optimum currency areas. American Economic Review 53: 509517.

Mundell R., 1961. A theory of optimum currency areas. American Economic Review 51: 657-665

Petersen M.A., 2009. Estimating standard errors in finance panel data sets: comparing approaches. Review of Financial Studies 22, 435-480.

Sinn H.-W., T. Buchen and T. Wollmershäuser, 2011. Trade imbalances: causes, consequences and policy measures. Ifo's Statement for the Camdessus Commission. CESifo Forum 12, 47-58.

Schmitz B. and J. von Hagen, 2009. Current account imbalances and financial integration in the euro area. CEPR Discussion Paper, 7262.

von Hagen J. and M.J.M. Neumann, 1994. Real exchange rates within and between currency areas: how far away is EMU? Review of Economics and Statistics 76, 236244. 
Tables

Table 1 -Descriptive statistics

\begin{tabular}{|c|c|c|c|c|c|c|}
\hline & \multicolumn{6}{|c|}{ Output synchronisation } \\
\hline & $\mathrm{N}$ & mean & median & sd & $\min$ & $\max$ \\
\hline Full sample & 7106 & -2.5034 & -1.7110 & 2.5329 & -18.3963 & -0.0005 \\
\hline EMU pairs & 2630 & -1.8431 & -1.3004 & 1.8321 & -11.1695 & -0.0006 \\
\hline Core vis-à-vis EMU & 1435 & -1.6189 & -1.1469 & 1.7021 & -11.1695 & -0.0006 \\
\hline Periphery vis-à-vis EMU & 1195 & -2.1125 & -1.5584 & 1.9438 & -10.4630 & -0.0037 \\
\hline Core EMU pairs & 715 & -1.2960 & -0.9749 & 1.4037 & -11.1695 & -0.0006 \\
\hline \multirow[t]{3}{*}{ Periphery EMU pairs } & 480 & -2.3694 & -1.8624 & 1.9736 & -8.5126 & -0.0179 \\
\hline & \multicolumn{6}{|c|}{ Trade intensity } \\
\hline & $\mathrm{N}$ & mean & median & sd & $\min$ & $\max$ \\
\hline Full sample & 7074 & 0.0061 & 0.0023 & 0.0105 & 0.0000 & 0.1345 \\
\hline EMU pairs & 2630 & 0.0105 & 0.0048 & 0.0149 & 0.0002 & 0.1345 \\
\hline Core vis-à-vis EMU & 1435 & 0.0142 & 0.0063 & 0.0184 & 0.0008 & 0.1345 \\
\hline Periphery vis-à-vis EMU & 1195 & 0.0060 & 0.0032 & 0.0067 & 0.0002 & 0.0368 \\
\hline Core EMU pairs & 715 & 0.0212 & 0.0098 & 0.0229 & 0.0016 & 0.1345 \\
\hline Periphery EMU pairs & 480 & 0.0043 & 0.0023 & 0.0051 & 0.0002 & 0.0254 \\
\hline
\end{tabular}

Output synchronisation is given by condition (2) in the main text and is measured as the negative of divergence in growth rates, defined as the absolute value of GDP differences between country $i$ and $j$ in a given year $t$. Trade intensity is given by condition (3) in the main text and is measured as the ratio of the sum of exports to and the $i$-th EMU country and its $j$-th trading partner, scaled by the sum of their nominal GDP levels. Sub-samples are defined in Section 2 of the main text. 
Table 2 - Temporal aggregation of year-by-year estimates

\begin{tabular}{ccc}
\hline \multicolumn{3}{c}{ EMU vs all } \\
$\gamma_{1}$ & 0.5342 & $(0.2211)$ \\
\hline \multicolumn{3}{c}{ EMU pairs vs extra-EMU partners } \\
$\gamma_{1}$ & 0.5927 & $(0.0672)$ \\
$\gamma_{2}$ & 0.6319 & $(0.1276)$ \\
$\gamma_{3}$ & -0.0312 & $(0.6353)$ \\
\hline Core EMU countries vs EMU and extra-EMU partners \\
$\gamma_{1}$ & 0.5585 & $(0.0650)$ \\
$\gamma_{2}$ & 0.6389 & $(0.1127)$ \\
$\gamma_{3}$ & -0.1504 & $(0.6172)$ \\
\hline
\end{tabular}

Peripheral EMU countries vs EMU and extra-EMU partners

\begin{tabular}{ccc}
$\gamma_{1}$ & 0.5527 & $(0.1564)$ \\
$\gamma_{2}$ & 0.6683 & $(0.1021)$ \\
$\gamma_{3}$ & -0.6241 & $(0.8587)$ \\
\hline
\end{tabular}

Core EMU country pairs vs other EMU and non-EMU partners

\begin{tabular}{ccc}
$\gamma_{1}$ & 0.4630 & $(0.0943)$ \\
$\gamma_{2}$ & 0.6528 & $(0.1130)$ \\
$\gamma_{3}$ & -0.6374 & $(0.7247)$ \\
\hline \multicolumn{2}{c}{ Peripheral EMU country pairs vs other EMU and non-EMU partners } \\
$\gamma_{1}$ & 0.5342 & $(0.2211)$ \\
$\gamma_{2}$ & 0.6691 & $(0.0988)$ \\
$\gamma_{3}$ & -0.7935 & $(1.0376)$ \\
\hline
\end{tabular}

Time series averages of the yearly slopes reported in Tables A1-A6 of the Appendix. Coefficients in bold and italics indicate statistical significance at the 5 and 10 percent nominal level (or better), respectively. Standard errors corrected by serial correlation according to Petersen (2009) in parentheses. 
Figure 1 - Descriptive statistics: GDP synchronisation

Panel A.

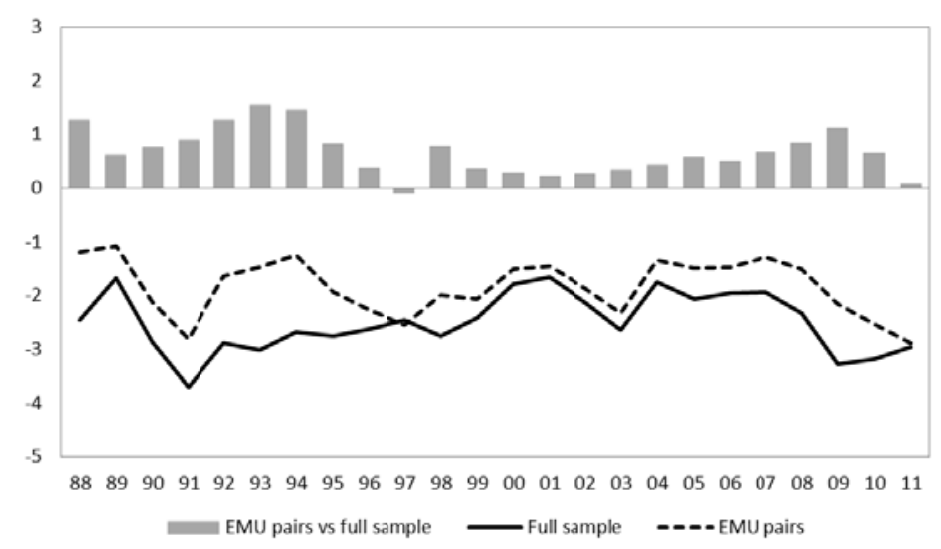

Panel B.

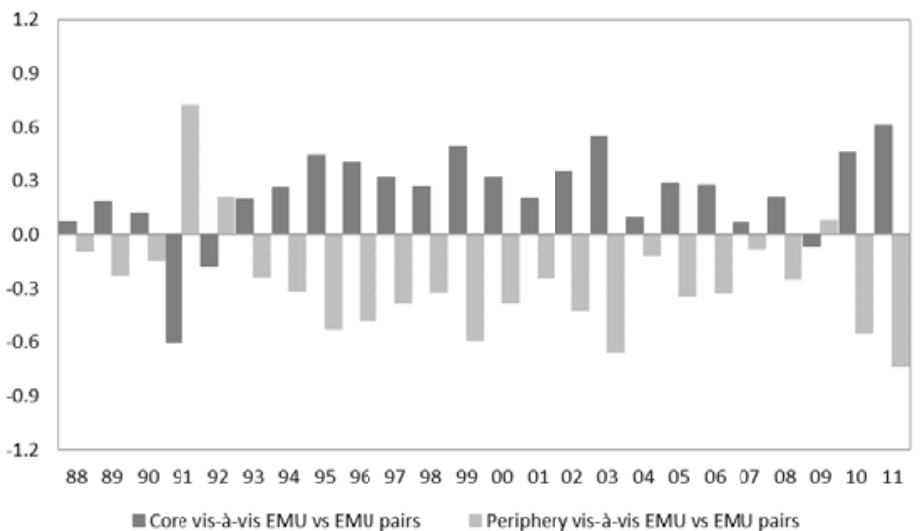

Panel C.

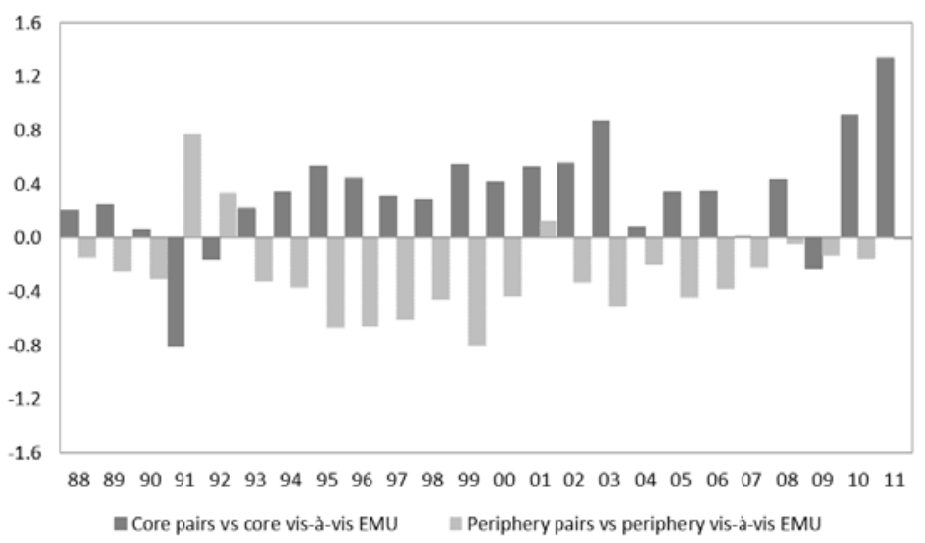

Panel A. Solid and dashed lines plot the output synchronisation measure (2) for the full sample and for EMU country pairs, respectively; bars: difference between the two lines. Panel B. Dark (light) bars: output synchronisation differential between core (peripheral) EMU countries vis-à-vis EMU countries and EMU country pairs. Panel C. Dark (light) bars: output synchronisation differential between core (peripheral) EMU pairs and core (peripheral) countries vis-à-vis EMU countries. Percentage values. 
Figure 2 - Descriptive statistics: trade intensity

Panel A.

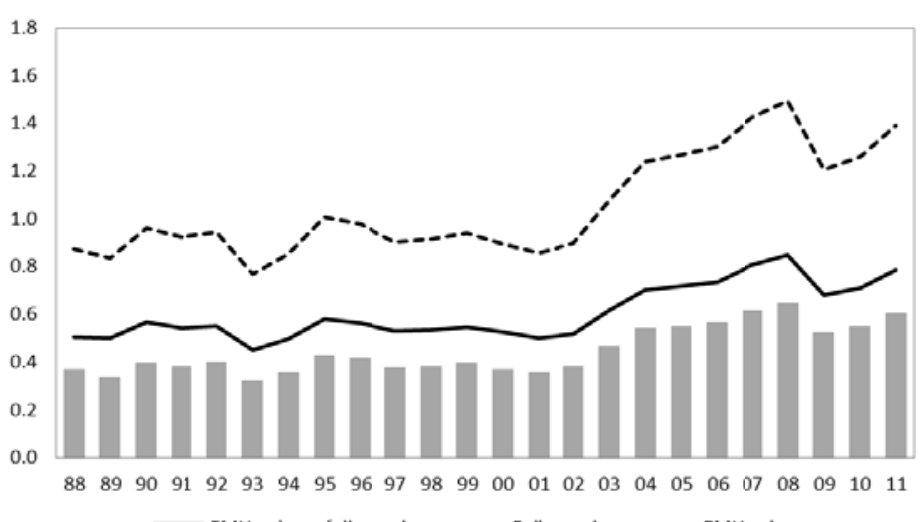

Panel B.

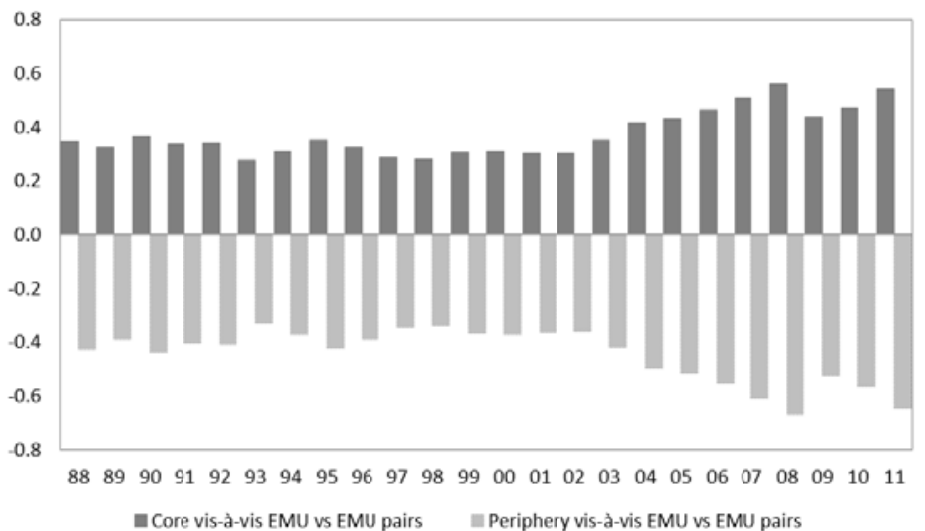

Panel C.

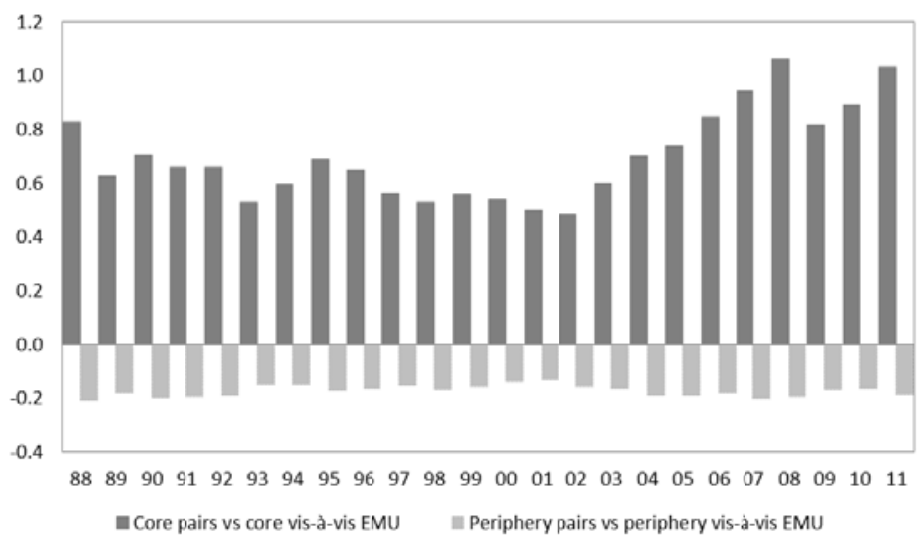

Panel A. Solid and dashed lines plot the trade intensity measure (3) for the full sample and for EMU country pairs, respectively; bars: difference between the two lines. Panel B. Dark (light) bars: trade intensity differential between core (peripheral) EMU countries vis-à-vis EMU countries and EMU country pairs. Panel C. Dark (light) bars: trade intensity between core (peripheral) EMU pairs and core (peripheral) countries vis-à-vis EMU countries. Percentage values. 
Figure 3 - Rolling estimates: EMU countries vs all partners

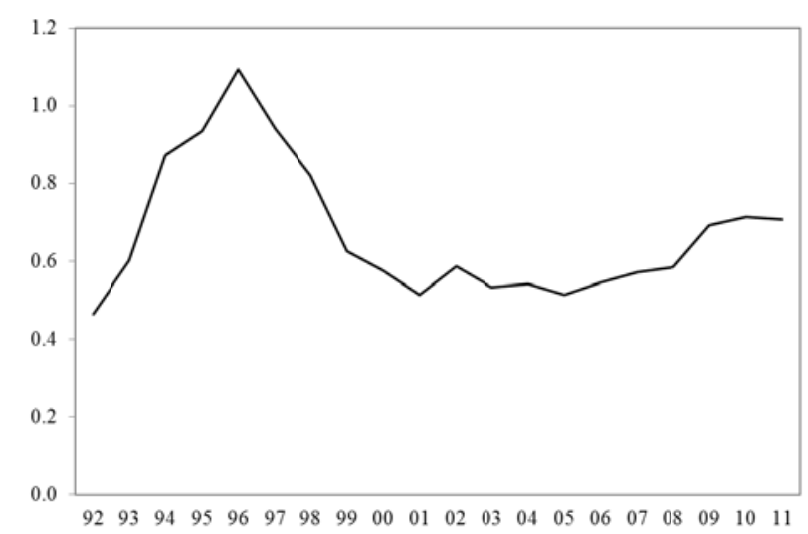

Rolling moving averages of the estimated parameter of condition (4) in the main text (5 years averages). 
Figure 4 - Rolling estimates: EMU pairs vs non-EMU partners

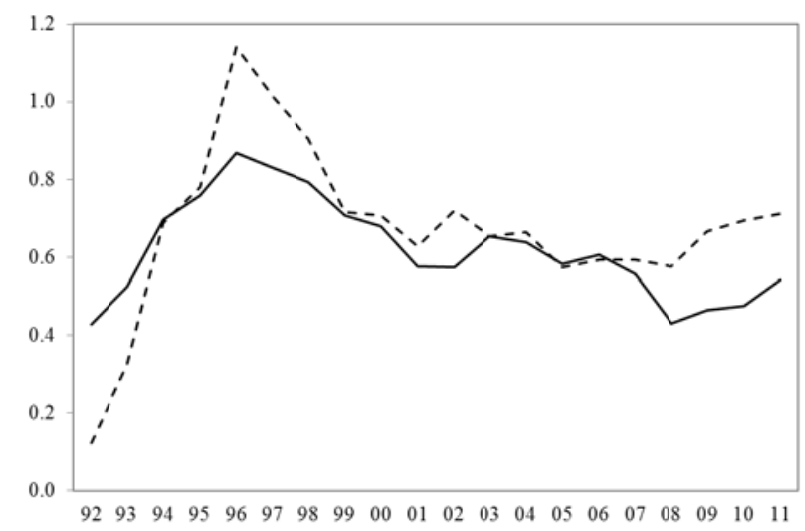

Rolling moving averages ( 5 years) of the estimated parameter of condition (5) in the main text for Panel A. reports the coefficients (solid line) and (dashed line). 
Figure 5 - Rolling estimates: core and peripheral EMU countries vs EMU and non-

\section{EMU partners}

\section{Panel A.}

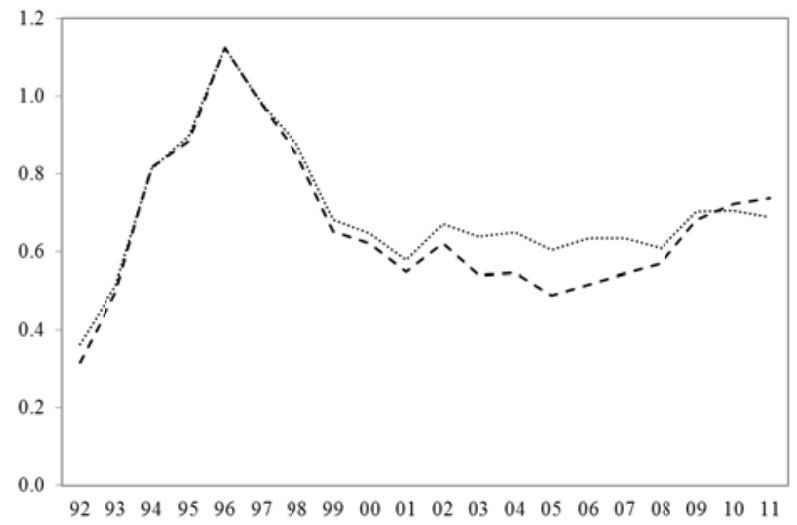

Panel B.

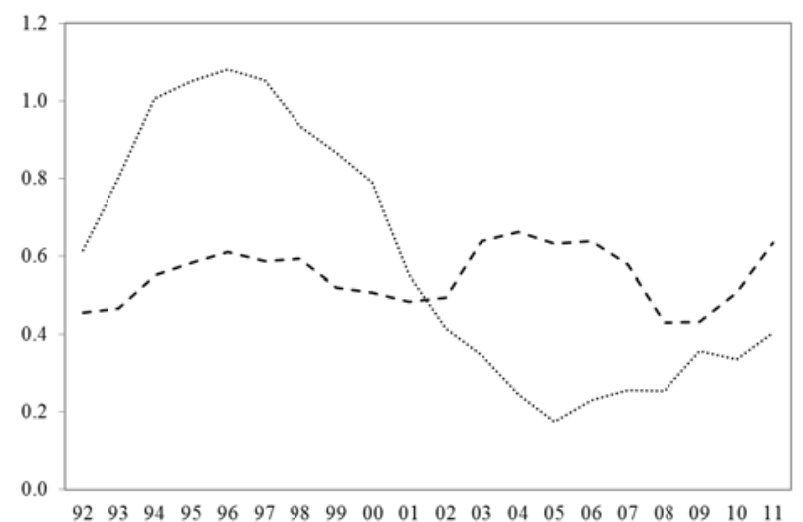

Rolling moving averages ( 5 years) of the estimated parameter of condition (5) in the main text for (dashed line) and (dotted line). Panel A and B report the 's, 's, respectively. 
Figure 6 - Rolling estimates: core and peripheral EMU pairs vs other EMU and nonEMU partners

Panel A.

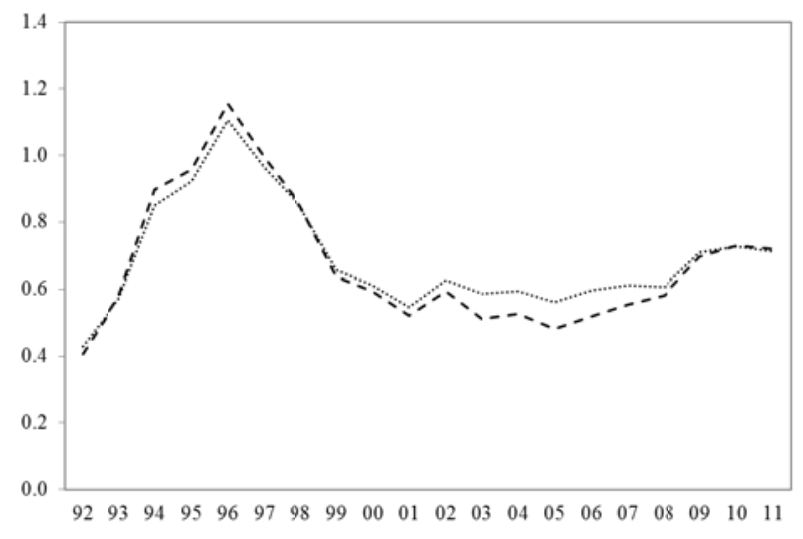

Panel B.

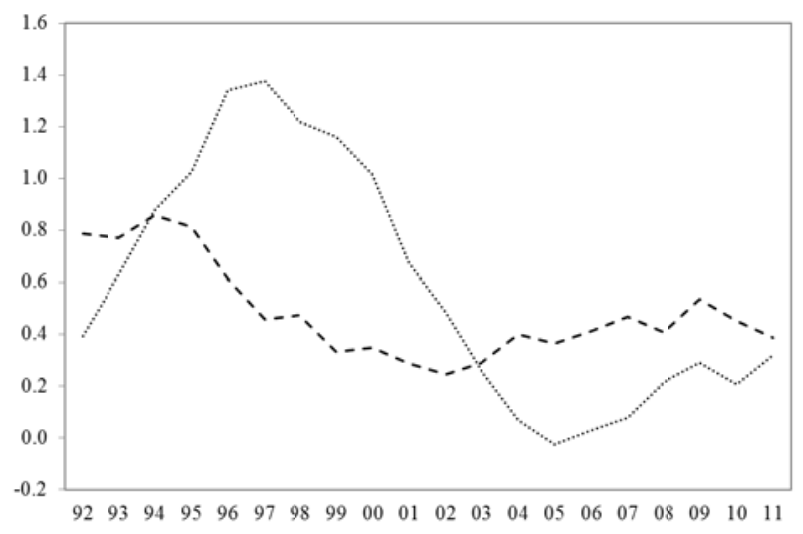

Rolling moving averages ( 5 years) of the estimated parameter of condition (5) in the main text for (dashed line) and (dotted line). Panel A and B report the 's, 's, respectively. 


\section{Appendix}

Table A.1 - EMU countries vs all partners

\begin{tabular}{|c|c|c|c|c|}
\hline & \multicolumn{2}{|c|}{$\gamma_{1}$} & $\mathrm{~N}$ & jp \\
\hline 1988 & 0.8346 & $(0.0919)$ & 275 & {$[0.130]$} \\
\hline 1989 & 0.1032 & $(0.0516)$ & 275 & {$[0.095]$} \\
\hline 1990 & 0.6019 & $(0.0577)$ & 286 & {$[0.173]$} \\
\hline 1991 & -0.1319 & $(0.1195)$ & 286 & [0.107] \\
\hline 1992 & 0.9101 & (0.1089) & 289 & {$[0.220]$} \\
\hline 1993 & 1.5205 & (0.1794) & 296 & {$[0.104]$} \\
\hline 1994 & 1.4579 & (0.1307) & 296 & {$[0.092]$} \\
\hline 1995 & 0.9165 & (0.1137) & 297 & [0.095] \\
\hline 1996 & 0.6606 & (0.1387) & 297 & {$[0.092]$} \\
\hline 1997 & 0.1497 & $(0.1163)$ & 297 & {$[0.095]$} \\
\hline 1998 & 0.9185 & $(0.0733)$ & 297 & {$[0.096]$} \\
\hline 1999 & 0.4798 & (0.1097) & 297 & {$[0.094]$} \\
\hline 2000 & 0.6695 & $(0.1407)$ & 297 & [0.097] \\
\hline 2001 & 0.3513 & $(0.0854)$ & 297 & {$[0.097]$} \\
\hline 2002 & 0.5139 & $(0.1494)$ & 297 & [0.169] \\
\hline 2003 & 0.6495 & (0.1759) & 297 & [0.119] \\
\hline 2004 & 0.5285 & $(0.0970)$ & 297 & {$[0.097]$} \\
\hline 2005 & 0.5209 & (0.1033) & 297 & {$[0.096]$} \\
\hline 2006 & 0.5207 & $(0.0745)$ & 297 & {$[0.093]$} \\
\hline 2007 & 0.6409 & $(0.0661)$ & 297 & {$[0.090]$} \\
\hline 2008 & 0.7073 & $(0.0702)$ & 297 & {$[0.092]$} \\
\hline 2009 & 1.0700 & $(0.0704)$ & 297 & [0.133] \\
\hline 2010 & 0.6340 & $(0.0929)$ & 297 & {$[0.100]$} \\
\hline 2011 & 0.4778 & $(0.0798)$ & 297 & {$[0.098]$} \\
\hline
\end{tabular}

Fixed effects IV estimation results of model (4), with distance (and its squared term), common border, common languages, the (log of) the size of the partner country and membership to WTO as external instruments. Coefficients in bold and italics indicate statistical significance at the 5 and 10 percent nominal level (or better), respectively. Robust standard errors obtained via clustering of the residual along the reporting country dimension in parentheses. p-value associated to the Hansen-J statistics for the null of no correlation between instruments and the disturbance process (jp) in square brackets. 
Table A.2 - EMU pairs vs non-EMU partners

\begin{tabular}{|c|c|c|c|c|c|c|c|c|}
\hline & \multicolumn{2}{|c|}{$\gamma_{1}$} & \multicolumn{2}{|c|}{$\gamma_{2}$} & \multicolumn{2}{|c|}{$\gamma_{3}$} & \multirow{2}{*}{$\frac{N}{275}$} & \multirow{2}{*}{$\frac{j p}{[0.147]}$} \\
\hline 1988 & 0.2251 & $(0.1114)$ & 0.6291 & $(0.1467)$ & -0.8564 & $(0.7443)$ & & \\
\hline 1989 & 0.0914 & $(0.0995)$ & -0.3155 & $(0.0702)$ & 3.5673 & $(0.4188)$ & 275 & [0.147] \\
\hline 1990 & 0.6225 & $(0.1421)$ & 0.4717 & (0.1511) & 1.1665 & $(0.9586)$ & 286 & {$[0.271]$} \\
\hline 1991 & 0.3199 & $(0.1853)$ & -0.9924 & $(0.3104)$ & 9.5454 & (1.5071) & 286 & {$[0.146]$} \\
\hline 1992 & 0.8784 & $(0.0954)$ & 0.8166 & $(0.1457)$ & 0.7014 & (0.8233) & 289 & [0.295] \\
\hline 1993 & 0.7058 & $(0.2114)$ & 1.6382 & $(0.2056)$ & -4.8291 & (1.3840) & 296 & {$[0.157]$} \\
\hline 1994 & 0.9510 & $(0.1661)$ & 1.5040 & $(0.1648)$ & -2.6786 & (1.2402) & 296 & {$[0.140]$} \\
\hline 1995 & 0.9433 & $(0.1362)$ & 0.9347 & (0.1305) & 0.0565 & (0.9991) & 297 & [0.152] \\
\hline 1996 & 0.8641 & $(0.2267)$ & 0.8166 & $(0.1556)$ & -0.3117 & (1.1926) & 297 & [0.143] \\
\hline 1997 & 0.6884 & $(0.2422)$ & 0.1709 & $(0.1508)$ & 2.3709 & (0.8633) & 297 & {$[0.162]$} \\
\hline 1998 & 0.5215 & (0.1919) & 1.1018 & $(0.1596)$ & -3.3284 & (0.6976) & 297 & [0.158] \\
\hline 1999 & 0.5226 & $(0.1489)$ & 0.5503 & $(0.1960)$ & -0.3381 & (0.9816) & 297 & {$[0.172]$} \\
\hline 2000 & 0.7943 & $(0.1426)$ & 0.8990 & $(0.2166)$ & -1.2864 & (1.0463) & 297 & {$[0.160]$} \\
\hline 2001 & 0.3497 & $(0.1218)$ & 0.4174 & $(0.1113)$ & -0.5501 & $(0.3451)$ & 297 & {$[0.151]$} \\
\hline 2002 & 0.6774 & $(0.1555)$ & 0.6326 & $(0.1682)$ & -0.1787 & $(0.8087)$ & 297 & {$[0.281]$} \\
\hline 2003 & 0.9220 & (0.1988) & 0.7665 & $(0.1726)$ & 0.2827 & (1.0552) & 297 & [0.194] \\
\hline 2004 & 0.4433 & $(0.1067)$ & 0.6014 & $(0.0984)$ & -0.9480 & $(0.5791)$ & 297 & {$[0.142]$} \\
\hline 2005 & 0.5248 & $(0.1119)$ & 0.4483 & $(0.0834)$ & 0.7061 & $(0.7497)$ & 297 & [0.149] \\
\hline 2006 & 0.4669 & $(0.1030)$ & 0.5136 & $(0.0972)$ & -0.1314 & $(0.4874)$ & 297 & [0.143] \\
\hline 2007 & 0.4275 & $(0.0622)$ & 0.6345 & $(0.0987)$ & -0.8149 & $(0.4502)$ & 297 & {$[0.140]$} \\
\hline 2008 & 0.2847 & $(0.0785)$ & 0.6772 & $(0.0947)$ & -1.4978 & $(0.7537)$ & 297 & [0.143] \\
\hline 2009 & 0.6224 & $(0.1592)$ & 1.0534 & $(0.1257)$ & -1.8585 & $(0.5704)$ & 297 & [0.154] \\
\hline 2010 & 0.5686 & $(0.1368)$ & 0.5914 & $(0.0981)$ & 0.1094 & $(0.7150)$ & 297 & [0.158] \\
\hline 2011 & 0.8099 & (0.1429) & 0.6037 & $(0.1136)$ & 0.3537 & (0.9153) & 297 & [0.198] \\
\hline
\end{tabular}

Fixed effects IV estimation results of model (5) with $k=1$ and distance (and its squared term), common border, common languages, the (log of) the size of the partner country and membership to WTO as external instruments. Coefficients in bold and italics indicate statistical significance at the 5 and 10 percent nominal level (or better), respectively. Robust standard errors obtained via clustering of the residual along the reporting country dimension in parentheses. p-value associated to the Hansen-J statistics for the null of no correlation between instruments and the disturbance process (jp) in square brackets. 
Table A.3 - Core EMU countries vs EMU and non-EMU partners

\begin{tabular}{llllllllc}
\hline & \multicolumn{3}{c}{$\gamma_{1}$} & \multicolumn{3}{c}{$\gamma_{3}$} & $\mathrm{~N}$ & $\mathrm{jp}$ \\
\hline 1988 & 0.2775 & $(0.1321)$ & $\mathbf{0 . 7 4 5 0}$ & $(0.1234)$ & -1.2198 & $(0.6422)$ & 275 & {$[0.170]$} \\
1989 & 0.2197 & $(0.1058)$ & -0.1080 & $(0.0776)$ & $\mathbf{2 . 7 1 2 1}$ & $(0.5676)$ & 275 & {$[0.140]$} \\
1990 & $\mathbf{0 . 5 7 4 6}$ & $(0.2259)$ & $\mathbf{0 . 5 6 4 5}$ & $(0.1037)$ & 0.2446 & $(1.0105)$ & 286 & {$[0.249]$} \\
1991 & $\mathbf{0 . 4 9 3 9}$ & $(0.1505)$ & -0.5019 & $(0.2644)$ & $\mathbf{6 . 6 0 9 4}$ & $(1.2628)$ & 286 & {$[0.144]$} \\
1992 & $\mathbf{0 . 7 1 6 3}$ & $(0.0551)$ & $\mathbf{0 . 8 8 4 9}$ & $(0.1361)$ & -0.4093 & $(0.6775)$ & 289 & {$[0.321]$} \\
1993 & $\mathbf{0 . 3 3 0 1}$ & $(0.0890)$ & $\mathbf{1 . 6 3 9 4}$ & $(0.2060)$ & $\mathbf{- 6 . 3 0 7 2}$ & $(1.1519)$ & 296 & {$[0.156]$} \\
1994 & $\mathbf{0 . 6 3 5 2}$ & $(0.1641)$ & $\mathbf{1 . 4 9 7 5}$ & $(0.1685)$ & -3.7533 & $(1.3506)$ & 296 & {$[0.141]$} \\
1995 & $\mathbf{0 . 7 3 6 8}$ & $(0.1536)$ & $\mathbf{0 . 9 0 0 8}$ & $(0.1488)$ & -0.4328 & $(1.2097)$ & 297 & {$[0.154]$} \\
1996 & $\mathbf{0 . 6 3 2 8}$ & $(0.2641)$ & $\mathbf{0 . 6 9 9 4}$ & $(0.1678)$ & -0.4364 & $(1.5792)$ & 297 & {$[0.141]$} \\
1997 & $\mathbf{0 . 6 0 4 2}$ & $(0.2554)$ & 0.1485 & $(0.1326)$ & 1.9735 & $(1.1593)$ & 297 & {$[0.151]$} \\
1998 & 0.3560 & $(0.1936)$ & $\mathbf{0 . 9 9 9 5}$ & $(0.1209)$ & -3.2169 & $(0.9196)$ & 297 & {$[0.157]$} \\
1999 & 0.2720 & $(0.1323)$ & $\mathbf{0 . 5 0 8 7}$ & $(0.1588)$ & -1.1070 & $(0.8835)$ & 297 & {$[0.161]$} \\
2000 & $\mathbf{0 . 6 6 9 9}$ & $(0.1201)$ & $\mathbf{0 . 7 4 5 5}$ & $(0.2043)$ & -0.6634 & $(1.2757)$ & 297 & {$[0.144]$} \\
2001 & $\mathbf{0 . 5 1 5 9}$ & $(0.0978)$ & $\mathbf{0 . 3 4 2 1}$ & $(0.1153)$ & 0.8815 & $(0.7937)$ & 297 & {$[0.150]$} \\
2002 & $\mathbf{0 . 6 5 8 9}$ & $(0.1644)$ & $\mathbf{0 . 5 0 9 7}$ & $(0.1895)$ & 0.8442 & $(1.3030)$ & 297 & {$[0.187]$} \\
2003 & $\mathbf{1 . 0 7 9 1}$ & $(0.0997)$ & $\mathbf{0 . 5 8 9 6}$ & $(0.2156)$ & 2.5400 & $(1.2836)$ & 297 & {$[0.191]$} \\
2004 & $\mathbf{0 . 3 9 0 2}$ & $(0.1341)$ & $\mathbf{0 . 5 4 2 4}$ & $(0.1141)$ & -0.6130 & $(0.8992)$ & 297 & {$[0.151]$} \\
2005 & $\mathbf{0 . 5 1 8 2}$ & $(0.1029)$ & $\mathbf{0 . 4 5 1 0}$ & $(0.1190)$ & 0.8928 & $(0.8355)$ & 297 & {$[0.159]$} \\
2006 & $\mathbf{0 . 5 4 7 7}$ & $(0.0438)$ & $\mathbf{0 . 4 8 4 3}$ & $(0.0913)$ & 0.5930 & $(0.4464)$ & 297 & {$[0.146]$} \\
2007 & $\mathbf{0 . 3 5 1 9}$ & $(0.0704)$ & $\mathbf{0 . 6 5 0 4}$ & $(0.0862)$ & -1.0881 & $(0.5327)$ & 297 & {$[0.140]$} \\
2008 & $\mathbf{0 . 3 3 6 4}$ & $(0.0983)$ & $\mathbf{0 . 7 1 7 3}$ & $(0.0852)$ & -1.4087 & $(0.7329)$ & 297 & {$[0.149]$} \\
2009 & $\mathbf{0 . 4 0 2 8}$ & $(0.0589)$ & $\mathbf{1 . 1 0 2 9}$ & $(0.102)$ & -2.8885 & $(0.4226)$ & 297 & {$[0.167]$} \\
2010 & $\mathbf{0 . 8 9 8 6}$ & $(0.0728)$ & $\mathbf{0 . 6 5 3 9}$ & $(0.0900)$ & 0.8932 & $(0.5444)$ & 297 & {$[0.156]$} \\
2011 & $\mathbf{1 . 1 8 5 6}$ & $(0.0669)$ & $\mathbf{0 . 5 6 5 2}$ & $(0.0835)$ & $\mathbf{1 . 7 4 9 4}$ & $(0.3797)$ & 297 & {$[0.198]$} \\
\hline & & & & & & & & \\
\hline
\end{tabular}

Fixed effects IV estimation results of model (5) with $k=2$ and distance (and its squared term), common border, common languages, the (log of) the size of the partner country and membership to WTO as external instruments. Coefficients in bold and italics indicate statistical significance at the 5 and 10 percent nominal level (or better), respectively. Robust standard errors obtained via clustering of the residual along the reporting country dimension in parentheses. p-value associated to the Hansen-J statistics for the null of no correlation between instruments and the disturbance process (jp) in square brackets. 
Table A.4 - Peripheral EMU countries vs EMU and non-EMU partners

\begin{tabular}{|c|c|c|c|c|c|c|c|c|}
\hline \multirow[b]{2}{*}{1988} & \multicolumn{2}{|c|}{$\gamma_{1}$} & \multicolumn{2}{|c|}{$\gamma_{2}$} & \multicolumn{2}{|c|}{$\gamma_{3}$} & \multirow{2}{*}{$\frac{\mathrm{N}}{275}$} & \multirow{2}{*}{$\frac{\text { jp }}{[0.105]}$} \\
\hline & 0.1136 & $(0.2062)$ & 0.7650 & $(0.1115)$ & -2.6076 & (1.2737) & & \\
\hline 1989 & 0.0958 & (0.1998) & -0.0023 & $(0.0883)$ & 1.5894 & (1.0490) & 275 & {$[0.091]$} \\
\hline 1990 & 0.8447 & $(0.1563)$ & 0.5471 & $(0.0806)$ & 2.0389 & (1.296) & 286 & {$[0.156]$} \\
\hline 1991 & 0.8750 & $(0.2327)$ & -0.3875 & $(0.1873)$ & 9.3323 & (1.9039) & 286 & {$[0.107]$} \\
\hline 1992 & 1.1457 & $(0.0669)$ & 0.8974 & (0.1194) & 1.5096 & $(0.9222)$ & 289 & {$[0.204]$} \\
\hline 1993 & 1.0426 & $(0.2465)$ & 1.5137 & $(0.1842)$ & -2.4936 & (1.7038) & 296 & {$[0.106]$} \\
\hline 1994 & 1.1201 & $(0.2736)$ & 1.4864 & $(0.1271)$ & -2.1471 & (1.7653) & 296 & {$[0.090]$} \\
\hline 1995 & 1.0676 & $(0.3610)$ & 0.9690 & $(0.0953)$ & 0.1362 & (2.0635) & 297 & [0.107] \\
\hline 1996 & 1.0337 & $(0.4490)$ & 0.7565 & $(0.1313)$ & 0.7176 & (2.5607) & 297 & {$[0.091]$} \\
\hline 1997 & 1.0014 & $(0.3913)$ & 0.1786 & $(0.1301)$ & 4.2285 & (1.8550) & 297 & [0.108] \\
\hline 1998 & 0.4510 & $(0.3688)$ & 0.9796 & $(0.0976)$ & -3.2131 & (1.6477) & 297 & [0.104] \\
\hline 1999 & 0.7769 & $(0.2369)$ & 0.5242 & $(0.1305)$ & 1.0264 & (0.9609) & 297 & {$[0.151]$} \\
\hline 2000 & 0.6784 & $(0.3678)$ & 0.7903 & $(0.1368)$ & -1.5251 & (1.8731) & 297 & {$[0.094]$} \\
\hline 2001 & -0.1495 & $(0.2273)$ & 0.4190 & $(0.0736)$ & -3.6180 & (1.2032) & 297 & [0.115] \\
\hline 2002 & 0.3144 & $(0.3308)$ & 0.6382 & $(0.1303)$ & -2.7378 & (1.9062) & 297 & {$[0.560]$} \\
\hline 2003 & 0.1078 & $(0.4052)$ & 0.8165 & $(0.1342)$ & -5.0900 & (2.4169) & 297 & [0.155] \\
\hline 2004 & 0.2712 & $(0.2230)$ & 0.5826 & $(0.0917)$ & -2.0346 & (1.3887) & 297 & [0.099] \\
\hline 2005 & 0.3247 & $(0.3737)$ & 0.5616 & $(0.0852)$ & -1.4465 & (2.3182) & 297 & {$[0.101]$} \\
\hline 2006 & 0.1302 & $(0.2503)$ & 0.5681 & $(0.0752)$ & -2.5437 & (1.3495) & 297 & [0.095] \\
\hline 2007 & 0.4425 & $(0.1586)$ & 0.6459 & $(0.0749)$ & -1.0118 & $(0.8177)$ & 297 & {$[0.090]$} \\
\hline 2008 & 0.1044 & $(0.1777)$ & 0.6835 & $(0.0736)$ & -2.5963 & $(0.9627)$ & 297 & [0.093] \\
\hline 2009 & 0.7782 & $(0.3262)$ & 1.0496 & $(0.0863)$ & -1.3558 & (1.3132) & 297 & [0.141] \\
\hline 2010 & 0.2201 & $(0.1575)$ & 0.5800 & $(0.1051)$ & -1.2447 & (0.9829) & 297 & {$[0.106]$} \\
\hline 2011 & 0.4733 & $(0.3156)$ & 0.4764 & $(0.0941)$ & 0.1079 & (1.8106) & 297 & {$[0.117]$} \\
\hline
\end{tabular}

Fixed effects IV estimation results of model (5) with $k=3$ and distance (and its squared term), common border, common languages, the (log of) the size of the partner country and membership to WTO as external instruments. Coefficients in bold and italics indicate statistical significance at the 5 and 10 percent nominal level (or better), respectively. Robust standard errors obtained via clustering of the residual along the reporting country dimension in parentheses. p-value associated to the Hansen-J statistics for the null of no correlation between instruments and the disturbance process (jp) in square brackets. 
Table A.5 - Core EMU country pairs vs other EMU and non-EMU partners

\begin{tabular}{|c|c|c|c|c|c|c|c|c|}
\hline \multirow[b]{2}{*}{1988} & \multicolumn{2}{|c|}{$\gamma_{1}$} & \multicolumn{2}{|c|}{$\gamma_{2}$} & \multicolumn{2}{|c|}{$\gamma_{3}$} & \multirow{2}{*}{$\frac{\mathrm{N}}{275}$} & \multirow{2}{*}{$\frac{\text { jp }}{[0.189]}$} \\
\hline & 0.3049 & $(0.1123)$ & 0.8323 & $(0.1212)$ & -1.9521 & $(0.7656)$ & & \\
\hline 1989 & 0.0954 & $(0.0502)$ & -0.0440 & $(0.0659)$ & 1.6830 & $(0.3887)$ & 275 & {$[0.140]$} \\
\hline 1990 & 0.7484 & $(0.1786)$ & 0.6069 & $(0.0905)$ & 0.4351 & $(1.0560)$ & 286 & [0.249] \\
\hline 1991 & 1.4512 & $(0.2613)$ & -0.3046 & $(0.1983)$ & 8.1986 & (1.9550) & 286 & {$[0.151]$} \\
\hline 1992 & 1.3304 & $(0.1424)$ & 0.9449 & (0.1299) & 1.2773 & $(0.8639)$ & 289 & [0.335] \\
\hline 1993 & 0.2297 & $(0.1652)$ & 1.6880 & $(0.2057)$ & -7.2381 & (1.1232) & 296 & [0.154] \\
\hline 1994 & 0.5313 & $(0.2083)$ & 1.5526 & $(0.1596)$ & -4.7567 & (1.2711) & 296 & {$[0.140]$} \\
\hline 1995 & 0.5267 & $(0.2042)$ & 0.9140 & (0.1353) & -1.3203 & (1.1186) & 297 & [0.159] \\
\hline 1996 & 0.4507 & $(0.2979)$ & 0.6816 & (0.1549) & -0.9431 & (1.5157) & 297 & {$[0.142]$} \\
\hline 1997 & 0.5490 & $(0.1511)$ & 0.1225 & $(0.1246)$ & 2.0450 & $(0.7878)$ & 297 & [0.155] \\
\hline 1998 & 0.3182 & $(0.2500)$ & 0.9823 & $(0.1016)$ & -3.1672 & (1.2110) & 297 & [0.156] \\
\hline 1999 & -0.1834 & $(0.1018)$ & 0.4803 & $(0.1408)$ & -2.4942 & $(0.7400)$ & 297 & {$[0.156]$} \\
\hline 2000 & 0.6018 & $(0.1622)$ & 0.7032 & $(0.1781)$ & -0.5002 & (1.2179) & 297 & [0.147] \\
\hline 2001 & 0.1494 & $(0.0935)$ & 0.3158 & $(0.0984)$ & -0.2423 & $(0.6555)$ & 297 & [0.165] \\
\hline 2002 & 0.3384 & $(0.2000)$ & 0.4906 & $(0.1695)$ & -0.1603 & (1.1512) & 297 & [0.358] \\
\hline 2003 & 0.5432 & $(0.2251)$ & 0.5659 & $(0.1942)$ & 0.8465 & (1.2596) & 297 & [0.185] \\
\hline 2004 & 0.3721 & $(0.2572)$ & 0.5618 & $(0.1108)$ & -0.9439 & (1.1637) & 297 & {$[0.151]$} \\
\hline 2005 & 0.4135 & $(0.1695)$ & 0.4753 & $(0.1130)$ & 0.3146 & $(0.8471)$ & 297 & {$[0.151]$} \\
\hline 2006 & 0.4038 & $(0.0809)$ & 0.4970 & $(0.0884)$ & -0.0394 & $(0.5452)$ & 297 & [0.143] \\
\hline 2007 & 0.6043 & $(0.0980)$ & 0.6701 & $(0.0846)$ & -0.4593 & $(0.5973)$ & 297 & {$[0.141]$} \\
\hline 2008 & 0.2424 & $(0.0911)$ & 0.7019 & $(0.0913)$ & -1.4930 & $(0.7107)$ & 297 & {$[0.150]$} \\
\hline 2009 & 1.0193 & $(0.0711)$ & 1.1445 & (0.1019) & -1.1818 & $(0.4677)$ & 297 & {$[0.180]$} \\
\hline 2010 & -0.0120 & $(0.1389)$ & 0.6307 & $(0.1089)$ & -2.2111 & $(0.6796)$ & 297 & {$[0.160]$} \\
\hline 2011 & 0.0822 & (0.0789) & 0.4526 & (0.1114) & -0.9951 & $(0.5227)$ & 297 & {$[0.192]$} \\
\hline
\end{tabular}

Fixed effects IV estimation results of model (5) with $k=4$ and distance (and its squared term), common border, common languages, the (log of) the size of the partner country and membership to WTO as external instruments. Coefficients in bold and italics indicate statistical significance at the 5 and 10 percent nominal level (or better), respectively. Robust standard errors obtained via clustering of the residual along the reporting country dimension in parentheses. p-value associated to the Hansen-J statistics for the null of no correlation between instruments and the disturbance process (jp) in square brackets. 
Table A.6 - Peripheral EMU country pairs vs other EMU and non-EMU partners

\begin{tabular}{|c|c|c|c|c|c|c|c|c|}
\hline & \multicolumn{2}{|c|}{$\gamma_{1}$} & \multicolumn{2}{|c|}{$\gamma_{2}$} & \multicolumn{2}{|c|}{$\gamma_{3}$} & \multirow{2}{*}{$\frac{N}{275}$} & \multirow{2}{*}{$\frac{\text { jp }}{[0.138]}$} \\
\hline 1988 & 0.2933 & $(0.2633)$ & 0.8066 & (0.0969) & -2.0424 & (1.6380) & & \\
\hline 1989 & 0.1025 & $(0.2275)$ & 0.0796 & $(0.0585)$ & 0.5406 & (1.2288) & 275 & [0.091] \\
\hline 1990 & 0.8116 & $(0.2254)$ & 0.5844 & $(0.0598)$ & 1.5792 & (0.9045) & 286 & [0.184] \\
\hline 1991 & -0.1926 & (0.1248) & -0.2115 & $(0.1292)$ & 2.2180 & (0.9399) & 286 & [0.146] \\
\hline 1992 & 0.9535 & $(0.2318)$ & 0.8886 & (0.1094) & 1.3360 & (1.7636) & 289 & {$[0.225]$} \\
\hline 1993 & 1.4645 & $(0.4872)$ & 1.5169 & (0.1779) & 0.2418 & (3.3218) & 296 & [0.106] \\
\hline 1994 & 1.3410 & $(0.4727)$ & 1.4720 & $(0.1286)$ & -0.5668 & (3.1177) & 296 & [0.092] \\
\hline 1995 & 1.5538 & $(0.5163)$ & 0.9449 & $(0.1162)$ & 2.9651 & (2.8645) & 297 & [0.106] \\
\hline 1996 & 1.3934 & $(0.4732)$ & 0.7018 & $(0.1411)$ & 3.0462 & (2.5151) & 297 & [0.092] \\
\hline 1997 & 1.1264 & $(0.3736)$ & 0.1734 & $(0.1246)$ & 4.8048 & (1.5877) & 297 & [0.111] \\
\hline 1998 & 0.6822 & $(0.3197)$ & 0.9432 & $(0.0858)$ & -1.8105 & (1.2353) & 297 & [0.102] \\
\hline 1999 & 1.0504 & $(0.3338)$ & 0.5178 & $(0.1225)$ & 2.1818 & $(1.2361)$ & 297 & [0.123] \\
\hline 2000 & 0.8296 & $(0.3297)$ & 0.7224 & $(0.1485)$ & -0.1651 & (1.7289) & 297 & [0.102] \\
\hline 2001 & -0.3261 & $(0.2459)$ & 0.3766 & $(0.0933)$ & -4.2124 & (1.2504) & 297 & {$[0.120]$} \\
\hline 2002 & 0.1803 & $(0.2523)$ & 0.5763 & $(0.1538)$ & -3.1697 & (1.0426) & 297 & [0.667] \\
\hline 2003 & -0.4487 & $(0.3702)$ & 0.7379 & $(0.1723)$ & -8.0547 & (1.8545) & 297 & [0.118] \\
\hline 2004 & 0.1105 & (0.1964) & 0.5590 & $(0.0973)$ & -2.8363 & (1.0769) & 297 & [0.096] \\
\hline 2005 & 0.3593 & $(0.3560)$ & 0.5554 & $(0.1006)$ & -1.5593 & (2.1000) & 297 & [0.098] \\
\hline 2006 & -0.0576 & $(0.2641)$ & 0.5581 & $(0.0749)$ & -3.8833 & (1.3220) & 297 & [0.096] \\
\hline 2007 & 0.4196 & (0.1798) & 0.6537 & $(0.0686)$ & -1.2855 & (1.1903) & 297 & [0.090] \\
\hline 2008 & 0.2511 & $(0.2470)$ & 0.7038 & $(0.0665)$ & -2.0029 & (1.2893) & 297 & [0.094] \\
\hline 2009 & 0.4756 & (0.1058) & 1.0805 & $(0.0755)$ & -3.2259 & $(0.5244)$ & 297 & [0.151] \\
\hline 2010 & -0.0593 & $(0.4296)$ & 0.6424 & $(0.0986)$ & -3.5751 & (2.6635) & 297 & [0.108] \\
\hline 2011 & 0.5069 & $(0.5688)$ & 0.4746 & $(0.0848)$ & 0.4335 & (3.2347) & 297 & [0.121] \\
\hline
\end{tabular}

Fixed effects IV estimation results of model (5) with $k=5$ and distance (and its squared term), common border, common languages, the (log of) the size of the partner country and membership to WTO as external instruments. Coefficients in bold and italics indicate statistical significance at the 5 and 10 percent nominal level (or better), respectively. Robust standard errors obtained via clustering of the residual along the reporting country dimension in parentheses. p-value associated to the Hansen-J statistics for the null of no correlation between instruments and the disturbance process (jp) in square brackets. 